\title{
Ring Chromosome 13 in an Infant Girl
}

\author{
Jodeiry $\mathrm{B}^{1}$, Rahmani $\mathrm{SA}^{2}$, Javaherizadeh $\mathrm{H}^{3}$, Mirnia $\mathrm{K}^{4}$
}

\begin{abstract}
Ring chromosome 13 , is an uncommon genetic syndrome. We report a girl infant with ring chromosome 13 . She is $2^{\text {nd }}$ offspring of family. She had no family history of genetic disorder. Karyotype showed 46xx,r(13). She had hypertelorism, wide nasal bridge, and long philtrum. She is the first report of ring chromosome 13 in Iranian children.
\end{abstract}

Key words: ring chromosome 13, hypertelorism, wide nasal bridge

\section{Introduction}

Cisti onstitutional ring chromosomes are rare and recognized in $1 / 25,000$ conceptions $^{1}$. Ring chromosome 13 accounts for $20 \%$ of ring chromosomes an compatible with life ${ }^{2}$. Ring chromosome 13 is associated with dysmorphic features, mental retardation, and delayed psychomotor development ${ }^{3}$.Ring chromosome 13 is associated with many of abnormality. We describe a girl infant with ring chromosome 13 . This may be the first report of ring chromosome 13 from Iran.

\section{The Case}

This newborn female with birth weight of 950 grams $\left(<3^{\text {rd }}\right.$ centile) gestational age 35 weeks was the second offspring of her family. Her father and mother were aged 29 and 32 years old respectively. There was no familial history of genetically syndrome among mother and father relatives. On examination the body length was 46.1 ( $5^{\text {th }}-10^{\text {th }}$ centile) and Upper limb/lower limb ratio was 1.68 (Upper limb 28cm, Lower limb 17.2). Infant had hypertelorism, microcephaly, and large ear. Neonatal reflexes and muscle tones were normal.

Prenatal sonography had shown Oligohydramnious. Parent's chromosomal study at cytogenetic levels was normal. For cytogenetic study, number of counted metaphase was 18 . Number of analyzed metaphase was 4 . The result of analysis was $46, \mathrm{XX}(\mathrm{r} 13)$ (Fig-1).

Follow-up at 4 months of age revealed ptosis of left eye. At 8 months ASQ (Ages and Stages Questionnaires) was done and the results were as shown in Table-1. There were delay in the
'Behzad Jodeiry' Assistant Professor of Paediatrics, Paediatric Health Research Center, Department of Paediatrics, Tabriz University of Medical Sciences, Iran. ${ }^{2}$ Seyed Ali Rahmani Assistant Professor of Medical Genetics, Ahar Isalamic Azad University, Iran. ${ }^{3}$ Hazhir Javaherizadeh Assistant Professor of Paediatrics, Faculty of Medicine, Ahvaz Jundishapur University of Medical Sciences, Ahvaz, Iran. ${ }^{4}$ Keyvan Mirnia Current Fellow of Neonatology, Department of Paediatrics, Tabriz University of Medical Sciences, Tabriz, Iran

\section{Address for correspondence}

Hazhir Javaherizadeh

E-mail: Hazhirja@yahoo.com

\section{How to cite}

Jodeiry B, Rahmani SA, Javaherizadeh H, Mirnia K. Ring Chromosome 13 in an Infant Girl. J Nepal Paediatr Soc 2014;34(1):74-76.

doi: http://dx.doi.org/10.3126/jnps.v34i1.7961

This work is licensed under a Creative Commons Attribution 3.0 License.

\section{(c) (i)}

communication, gross motor, and personnel social. Further follow up at nine months when the child was examined it was found that the corrected age was 8 month, body weight, head circumference, body length was 5800 grams $\left(<3^{\text {rd }}\right.$ centile) $37.5 \mathrm{~cm}$ ( $<3^{\text {rd }}$ centile), and $62.5 \mathrm{~cm}\left(<3^{\text {rd }}\right.$ centile) respectively (Fig-3). Body length was 62.5 $\mathrm{cm}\left(<3^{\text {rd }}\right.$ centile) and upper limb/lower limb ratio was 1.71 (Upper limb=39.5, Lower $\operatorname{limb}=23)$.

There was no hydrocephaly or ventriculomegaly in the brain CT. Anterior fontanel was open. Cranial sutures were open but slightly small than appropriate 
for age. Increased bone density was found around the posterior sagittal suture. Echocardiography and sonography were normal. Rolling and crawling was negative for her. ASQ test was done and the result was shown in Table-1. As shown in Table-1, there is delay in three area of development. Child was examined at 12 months of age. Hypertelorism, left eye ptosis, simian crease, wide nasal bridge, long philtrum were found in physical examination. ASQ was done and there was a delay in all items. Head circumference was $41 \mathrm{~cm}\left(<3^{\text {rd }}\right.$ centile) at 13 month of age. Six teeth had erupted.

Investigations revealed: TSH was 14, followed by 10 and 6.7 later. T4 was 8.86 (Normal range: 4.512.5), Free T4:1.31 (Normal range:0.8-2), and TSH:2.6 (Normal range:0.39-6.16). On consultation with the paediatric endocrinologist, patient was followed without treatment.

Table 1: Result of ASQ test

\begin{tabular}{|l|c|c|}
\hline & $\mathbf{8}$ months & 12 months \\
\hline Communication & $25 / 36.5^{*}$ & $5 / 15.8^{*}$ \\
\hline Gross motor & $10 / 26.3^{*}$ & $0 / 18^{*}$ \\
\hline Fine Motor & $60 / 36.5$ & $20 / 28.4^{*}$ \\
\hline Problem Solving & $40 / 32.5$ & $20 / 25.2^{*}$ \\
\hline Personal Social & $20 / 30.5^{*}$ & $5 / 20.1^{*}$ \\
\hline
\end{tabular}

* Delay in development

\section{Discussion}

Lejune et al described ring chromosome 13 at $1968^{4}\left({ }^{1}\right)$. Ring chromosome 13 is relatively uncommon genetic disorder with estimated incidence of 1/58,000 of live birth ${ }^{5}$. Also there is some reports of ring chromosome 13 in some countries ${ }^{6,7}$. It is the first report of ring chromosome 13 in Iran.

The clinical presentation of ring chromosome 13 may be variable ${ }^{8}$. Niebur and Ottosen ${ }^{9}$ suggested there distinct clinical syndrome for ring chromosome 13; group I, is associated with severe mental retardation, microcephaly, true hypertelorism, salient frontal bossing erasing the nasal bridge, and large ear with deep sulci. Our case had hypertelorism, microcephaly, and large ear which was similar to group I of Niebur and Ottosen classification ${ }^{9}$. Group II, is associated with clinical manifestation of group $I$ in addition to foot and toe abnormalities, severe genital malformation, anal atresia, and eye malformation. Group III is characterized by retinoblastoma ${ }^{9}$. Other association with the syndrome includes retinal detachment ${ }^{10}$, imperforate anus, iris coloboma, and developmental anomalies of the brain ${ }^{11}$.

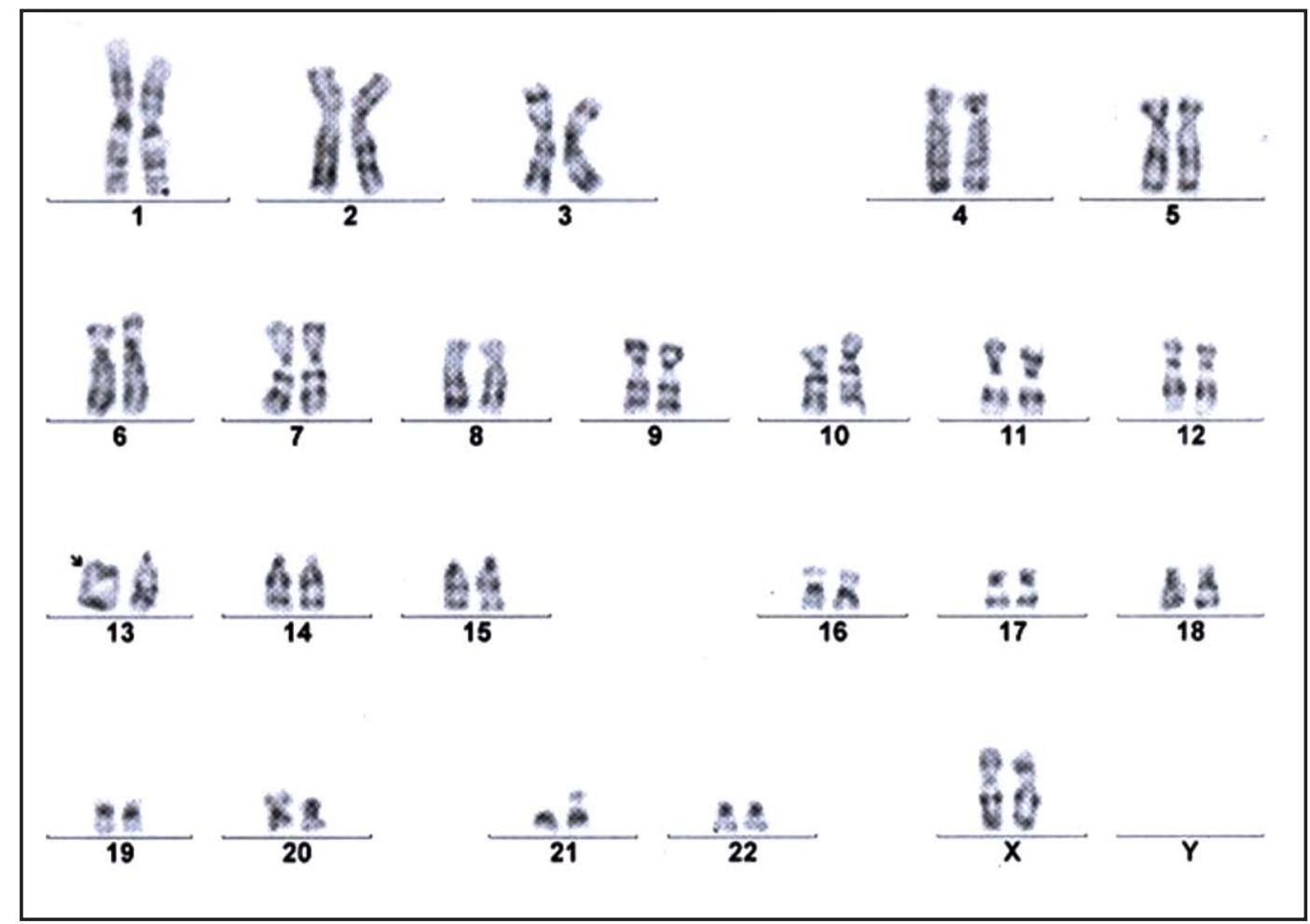

Fig 1: Karyotype of female infant with ring chromosome 13. 
Our case seems to be in group I. Our case showed delay development in gross motor, communication, and personal-social skill in eight month of age. After four month of follow-up, she had delay in all of the items (communication, gross motor, fine motor, problem solving, and personal social skill). Hypertelorism and large ear were other findings and were consistent with Group I classification. Also there was some abnormality it the results of thyroid hormone, according to consultation with the paediatric endocrinologist infants received no treatment and were placed under observation.

Anencephaly was reported in association with ring chromosome $13^{12}$. There is report of hypertelorism as one of clinical manifestation of ring chromosome $13^{13}$. This case may be the first report of ring chromosome 13 among Iranian population.

\section{Conclusion}

It is important for physicians to investigate cases to detect genetic abnormality and appropriate consultation to prevent such problems.

\section{References}

1. Jacobs PA. Mutation rates of structural chromosome rearrangements in man. Am J Hum Genet 1981;33:44-54.

2. Bargaonkar DS. Chromosomal variation in man: a catalog of chromosomal variants and anomalies. $8^{\text {th }}$ ed New York: Wiley-Liss; 1997.

3. Uwineza A, Pierguin G, Gaillez S, Jamar M, Hellin AC, Caberg JH, Bours V. Clinical, cytogenetic and molecular characterization of two cases of mosaic ring chromosome 13. Genet Couns 2013;24(2):193200.
4. Lejune J, Lafourcade J, Berger $\mathrm{R}$, et al. The Dr genotype a study of three cases with a ring $D$ chromosome. Ann Genet 1968;11:79-87.

5. Martin Nicole J, Harvey Phillip J. The ring chromosome 13 syndrome. Hum Genet 1982;61:18-23.

6. Lee JS, Jung YT, Lim BH, Kang IJ, et al. A case of 13ring chromosome syndrome. J Korean Pediatr Soc 1991;34(12):1736-9.

7. Lee YA, Lee DG, Chung WK, Cho HC, Chi JG. An autopsy case of 13 ring chromosome syndrome. $J$ Korean Soc Neonatol 1995;2:253-7.

8. Brown S, Russo J, Chitayat D, Warburton D. The 13qsyndrome: the molecular definition of a critical deletion region in band 13q32. Am J Hum Genet 1995;57:859-66.

9. Niebuhr E, Ottosen J. Ring chromosome $\mathrm{D}(13)$ associated with multiple congenital malformations. Annals de Genetiques 1973;16:157-66.

10. Filous A, Raskova D, Kodet R. Retinal detachment in an infant with the ring chromosome 13 syndrome. Acta Ophtalmol Scand 1998;76:739-41.

11. Parcheta B, Wisniewski L, Piontek E, Szymanska J, Skawisnki W, Wermenski K. Clinical features in a case with ring chromosome 13. Eur J Pediatr 1985;144:409-412.

12. Brandt CA, Hertz JM, Petersen MB, Vogel F, Noer $H$, Mikkelsen M. Ring chromosome 13: Lack of distinct syndromes based on different breakpoints on 13q. J Med Genet 1992;29:704-08.

13. Kim SY, Oh SM, Kim MJ, et al. A case of mosaic ring chromosome 13 syndrome. Korean J Pediatr 2009;52:242-246. 